\title{
Cultural Centrality and Information And Communication Technology among CANAdian Youth
}

\author{
VICTOR THIESSEN \\ E. DiAnne LoOKeR
}

Abstract. This paper examines the positions of First Nations, Inuit, and Métis (FNIM) peoples, and visible minorities as distances from the cultural "centre" of White European culture. It then assesses the relation of information and communication technology (ICT) to these locations among Canadian youth using three data sets: the 2001 Aboriginal Peoples Survey, the 2000 Youth in Transition Survey (older cohort) and its 2002 follow-up, and a 2004-2005 survey collected by the authors. Findings indicate that the idea of cultural centrality is useful in locating FNIM groups and visible minorities vis-à-vis the cultural centre and each other and highlighting the stratified heterogeneity of these groups. Access to, use of, and development of ICT skills tend to mirror the relative positions of these groups in terms of cultural centrality. Further, youth who retain close ties with traditional culture are less likely to develop facility with ICT.

Résumé. Cet article examine les positions des Premières nations, des Inuits et des Métis (FNIM) et des minorités visibles comme étant distanciés du «centre» culturel de la culture des Européens blancs. L'article évalue ensuite la relation entre les technologies de l'information et des communications (TIC) et ces endroits chez les jeunes Canadiens, au moyen de trois ensembles de données: l'Enquête auprès des peuples autochtones de 2001, l'Enquête auprès des jeunes en transition de 2000 (cohorte plus âgée) et le suivi de 2002, ainsi qu'une enquête faite par les auteurs en 2004-2005. Les conclusions révèlent que l'idée d'une centralité culturelle est utile pour situer les groupes FNIM et les minorités visibles par rapport au centre culturel et l'un à l'autre, et pour souligner l'homogénéité stratifiée de ces groupes. L'accès aux compétences en TIC, leur utilisation et leur développement a tendance à refléter les positions relatives de ces groupes en termes de centralité culturelle. De plus, il est moins improbable que les jeunes qui conservent des liens étroits avec la culture traditionnelle développent des capacités en TIC.

We would like to thank the editors and anonymous reviewers of CJS, as well as Charlotte Loppe, Howard Ramos, Jennifer Jarman, and Michael Jeffrey for helpful comments. 


\section{INTRODUCTION}

ncredible investments in Information and Communication Technology (ICT) have been expended by governments, communities, families and individuals. Underpinning these investments, governments stress the importance and potential payoff of ICT in a more and more global and information based society. Reflecting this focus on ICTs, Graham (2002:36) argues that

the explosion in the use of ICTs overwhelmingly represents an extraordinary extension in the social, economic, cultural and geographical powers of those groups and organisations who are best connected, most highly skilled and most able to organise and configure the shift on-line to their own advantage.

Parents also believe that ICT plays an essential role in their children's future life chances. About 90 percent of parents in the United States report that ICT will improve their children's academic performance (Turow and Nir 2000) and accordingly invest in home ICT resources (Lenhart 2003). Canadian research shows similar results (Ipsos-Reid 2005). We agree with Bourdieu that many behaviours of parents can be understood as dynamics of status reproduction (Bourdieu and Boltanski 1978:214). We see ICT as a form of capital which, like other forms of capital, can be converted into other desired outcomes such as employment.

This paper examines the effect of investments in access to, use of, and facility with ICT for cultural and racial groups within Canada. Canada officially recognizes three aboriginal groups: Inuit, North American Indian, and Métis. We use the term First Nations (FN) when specifically referring to North American Indians, the acronym FNIM when speaking collectively of First Nations, Inuit, and Métis, and the term "population groups" to refer to groups defined by their racial or ethnic identities.

This examination will identity the extent of any "digital divide" based on race and culture. By documenting differential rates of diffusion of this technology within different subgroups, we highlight the nature of other divides within Canada. Minority racial groups have less access to ICT than the dominant (White, European) group in North America, reflecting socioeconomic and other inequalities (Chakraborty and Bosman 2005; Hoffman, Novak, and Schlosser 2001). Using the concept of cultural centrality, our analysis goes beyond this simple dichotomy to explore the cultural and racial divisions within Canada. 


\section{Cultural Centrality}

Canadian society contains a dominant hegemonic economic and cultural core. Various population groups occupy positions at unequal physical, social, and cultural distances from this core. The physical component captures the spatial dimension of cultural centrality: the effect of living in a remote or isolated region rather than in a major metropolitan city. The social component refers to the extent of interaction with members and institutions of the cultural centre. For example, First Nations living on a reserve have fewer occasions to interact with White institutions and members than do their counterparts living off-reserve. Finally, the cultural component refers to lifestyle and value congruence of any group relative to that of the dominant group.

We chose the term cultural centrality to signal that centrality is determined by more than economic factors. In the Canadian context, the importance of cultural factors in the stratification system is manifested by the "Anglo-conformity" imperative (Breton 1998). Breton argues that violation of this imperative relegates one to lower rungs of the socioeconomic order. This argument has its roots in Porter's (1965) "blocked mobility" thesis, in which ethnic attachment was thought to reduce an ethnic group's chances for upward mobility.

The first task is to document the relative positions of the population groups on a variety of indicators relevant to the concept of cultural centrality. Overall consistency in their relative positions is essential to the potential fruitfulness of this concept. The next step examines the extent to which access, use, and skill development with ICT mirrors a group's distance from the cultural centre. If they do, we would argue that ICT is unlikely to mitigate existing inequities among the groups. On the other hand, if ICT related measures do not mirror these relative locations, the optimism of those who promote ICT as convertible into other forms of capital may be warranted.

\section{Literature ReVIEW}

In Porter's (1968:761) classic study of Canada's economic elite more than a half century ago, he noted that despite Canada being a multicultural and ethnically diverse society, "economic power is almost exclusively held by the English-speaking group of British origin which makes up less than half of the general population." While this portrayal was accurate at the time, economic power and associated privileges are now shared with those of Northern Europe and Jewish ancestry (Gosine 2000). Ra- 
cial identities, however, remain fundamental to understanding the current Canadian social structure (Geschwender and Guppy 1995; Gosine 2000; Hou and Balakrishnan 1996; Pendakur and Pendakur 2002; Siggner and Costa 2005).

A review of national studies supports the following conclusions regarding educational achievement and earnings of FNIM peoples and visible minorities:

- FNIM peoples have the lowest educational attainments and are the most likely of the different cultural groups to leave school prior to completing high school (Geschwender and Guppy 1995; Siggner and Costa 2005).

- A substantial earnings gap exists between FNIM peoples and most nonvisible minority groups, a gap that is reduced but not eliminated after the introduction of appropriate statistical controls (Geschwender and Guppy 1995; Pendakur and Pendakur 2002; Siggner and Costa 2005); only in the Geschwender and Guppy (1995) study does the gap vanish.

- Education yields lower returns to certain racial groups, which Geschwender and Guppy (1995) call the "ethnic penalty" and which also seems to apply to African Canadians (Gosine 2000). (See also Gosine 2000; Hou and Balakrishnan 1996; Pendakur and Pendakur 2002).

With the notable exception of Pendakur and Pendakur (2002), these national studies contrast either FNIM peoples or visible minorities with other Canadians, but do not compare FNIM peoples with visible minorities. As a result, evidence regarding the position of FNIM peoples relative to native-born visible minorities is scant. Pendakur and Pendakur (2002), however, consistently found that, in the censuses between 1971 and 1996, FNIM men were at the bottom of the earnings distributions, African Canadians next to the bottom, and Japanese always at the top, while the position of other ethnic groups varied. In the 1996 census, the rank order of earnings for various population groups was:

FNIM $<$ African Canadian $<$ South Asian $<$ Chinese $=$ White $<$ Japanese .

This is a solid start in locating population groups within Canada's stratification system and in differentiating the conditions of FNIM peoples from those of visible minorities. However, with one important exception (Kuhn and Sweetman 2002), FNIM peoples were treated as a single group. Although Kuhn and Sweetman do not distinguish between First Nations, Inuit, and Métis per se, they make three important distinctions among aboriginal groups: 1) on- versus off-reserve First Nations; 
2) those with ancestral intermarriage versus those without; and 3) those living in Nunavut, the Northwest Territories, or the Yukon versus those living in the Canadian provinces. These distinctions are relevant to our cultural centrality argument. The north-south criterion essentially selects Inuit Canadians, while both the on-off reserve and ancestral intermarriage status constitute important indicators of amount of contact with White Canadians, and are therefore indicators of cultural centrality. For all measures of desirable labour market experiences (employed, in the labour force, full-time full-year job, and earnings), Kuhn and Sweetman found the following rank order for the south:

on-reserve < off-reserve,

ancestral intermarriage $<$ off-reserve,

no intermarriage $<$ White

Further, they document a greater gap in all labour market outcomes between aboriginal and nonaboriginals in the North than the corresponding southern gap, suggesting that the labour market position of the Inuit may be even worse than that of on-reserve First Nations. The authors conclude that the amount of "contact/assimilation" with the "dominant culture" provides the most parsimonious explanation for their findings. Their contact/assimilation concept is compatible with our concept of cultural centrality.

We expand the examination of population group inequalities by assessing the relative positions of the Inuit, First Nations, Métis, those of aboriginal descent but not identifying themselves with any of the previous groups (nonidentifiers), African Canadians, Asians, and Whites. Since the conditions facing First Nations peoples living on reserves are quite distinct from those living off-reserve, and since this distinction is also important to their cultural centrality, they are subdivided on this criterion. Based on our review of the empirical literature their relative locations seem to be:

Inuit $<$ FN on-reserve $<$ FN off-reserve $<$ Métis $<$ FNIM nonidentifiers $<$ African Canadian $<$ Asian $<$ White

Our analysis provides additional evidence for this rank order of current Canadian society. We provide analyses that assess the relationship of this location to access and use of ICT.

Our focus is on young people, since it is here that the familial dynamics of intergenerational status maneuvering is most pronounced. Young people prepare themselves for productive membership in their society, and their parents make investments to maximize their children's chances for productive membership. To succeed in this venture, young people 
must also engage in activities and take on values and dispositions that allow the conversion of their parents' economic, social, and cultural capital to increase their own capital.

The concept of cultural centrality assesses the potential of ICT access, use, and skills to mitigate the race and culture inequities built into Canada's stratification system (see Alkalimat and Williams 2001 for a discussion of the importance of ICT and "cyberpower" to racial minority groups). If, for example, Inuit or Métis youth exceed their White counterparts in accumulated ICT capital, the potential of ICT to introduce changes and mitigate other inequities would be high. On the other hand, if the accumulated ICT capital between the different cultural and racial groups mirrors the current rank order, we would conclude that ICT will act to entrench rather than change the current structure.

Three components of ICT as a form of capital are considered in this paper:

- ICT resources (technological capital): a home computer with an internet connection.

- ICT skills (human capital): the ability to use a wide variety of computer applications effectively.

- Dispositions (habitus): perceptions, values, and attitudes towards ICT.

\section{DATA}

No single data set exists that can explore all aspects of the topic of this paper. For this reason, we weave together different components of the argument using three Canadian data sets ${ }^{1}$ to assess cultural centrality and its relation to ICT:

1. the 2001 Aboriginal Peoples Survey (APS),

2. the 2000 Youth in Transition Survey (YITS) of 18-20 year olds and the 2002 follow-up survey,

3. the primary data collected by the authors, which sampled high school students in selected schools in Nunavut and Nova Scotia. ${ }^{2}$

1. Since ICT changes so quickly, there is the perpetual danger that data are outdated before they can be analyzed in detail. These are the most recent nationally representative data sets available that have details on both ICT use and aboriginal status. The authors' data set is more recent, but more geographically limited.

2. The authors acknowledge funding from the Social Sciences and Humanities Research Council of Canada and access to the national data sets through Statistics Canada's Research Data Centres, which made this research possible. 
The sampling frame for Statistics Canada's APS was based on information about FNIM ancestry, treaty status, and status of living on or off a reserve, information contained in the 2001 Canadian census long form (administered to 20 percent of the population). For most of our analyses, only respondents who were between the ages of $15-24(\mathrm{~N}=16,104)$ are included. The data were weighted to make the results as representative of FNIM living in Canada as possible (see Statistics Canada 2003a for details). The baseline YITS surveyed residents of the ten Canadian provinces who turned 18-20 years of age during 1999. The sampling frame excludes persons living in the northern territories, those on First Nations reserves, as well as full-time members of the armed forces and inmates of institutions. Computer-assisted telephone interviews were completed with 23,592 youth (see Statistics Canada 2003b). In 2004-2005, the authors collected primary data from 2,258 students in thirteen high schools in Nunavut and ten in Nova Scotia, ${ }^{3}$ including one school on a First Nations reserve.

\section{Measures}

\section{Population Group}

Self-identification is our indicator of population group membership. In the APS such identity was tapped through the question "Are you an aboriginal person, that is, North American Indian, Métis or Inuit?” For multiple responses, respondents who lived in one of the northern territories and indicated Inuit as well as one or more other identities, were classified as Inuit; respondents who reported North American Indian in addition to one or more other identities were classified as First Nations. Respondents who claim FNIM ancestry but who did not select any of the three FNIM identities are designated as "nonidentifiers."

In the YITS survey, respondents were asked to identify their cultural or racial background from a list: White, Aboriginal, Black, and a variety of Asian groups, which we combined due to the small number of cases. Respondents who chose both a White and non-White background were classified as a member of the particular non-White group. With this classification, the YITS sample contains 546 (off-reserve) First Nations youth, 315 African Canadians, 874 youth who identified themselves as Asian and 16,134 White youth.

3. Grades 9-12 were sampled in Nunavut, grades 10-12 in Nova Scotia, reflecting the grades included in high school in the two locales. Details of the survey and sampling procedures can be found at www.equityandtechnology.com. 
In the authors' data, respondents were presented with a similar list. African Canadian and Other African descent were combined, as were Mi'kmaq and Other First Nations, as well as Asian Canadian and Other Asian Descent. In general, with multiple responses, if a student indicated two or more racial identities, they were assigned to the group considered more distant from the cultural centre. If no response was given to the question, and the school was located in Nunavut, the student was classified as Inuit. If no response was given and the school was located on a reserve, the student was classified as First Nations. Responses of "Other" and all other nonresponses to ethnic self-identification were classified as White. The sample contained 521 Inuit, 147 First Nations (almost exclusively on-reserve), 131 African Canadian, 49 Asian and 1,410 White students.

\section{Racial/cultural Identification}

It is important to assess the extent to which group members identify with their cultural or racial group. One key aspect of this identification is facility with, and importance of the retention of, a native language other than one of the two official languages in Canada.

The APS contained several questions regarding facility in an aboriginal language, which were combined on a four-point scale, where $1=$ never understood or spoke, $2=$ formerly understood or spoke, $3=$ currently understands or speaks, and $4=$ first language was an aboriginal language and is still spoken. Additionally, respondents were asked how important facility in an aboriginal language was for them, with four response categories ranging from "not important" to "very important." These two items were combined and converted to standard scores, with a Cronbach's $\alpha$ of 0.66 .

The authors' study asked four questions about language facility and the importance of retaining such facility: which languages they speak, which one they use most often, how well they can use these languages in writing (on a four-point scale from "not at all" to "very well"), and which ones they want their children to be able to speak as adults. Responses were collapsed to reflect facility in a language other than French or English. Principal components analysis (PCA) extracted a single factor which accounted for 69 percent of the variance. Cronbach's $\alpha$ for the resulting standardized factor score was 0.78 .

\section{Technological Capital (Home Access to ICT)}

The APS survey contains two items: whether in the past year the respondent used a computer at home, and whether the respondent had ac- 
cessed the Internet from home. The YITS survey contains no measure of ICT access, while in the authors' study, three measures of home access to ICT were available:

1. "How many computers are there in your home?"

2. "How many of these have an Internet connection?"

3. "What type of Internet connection do you have at home?" coded lowspeed (dial-up) or high-speed (cable, satellite).

\section{ICT Human Capital Skills}

The APS survey contains no measures of ICT skills, while the YITS survey has only a single measure of self-assessed computer skills: "How would you rate your ability to use a computer (for example, using software applications, programming, using a computer to find or process information)?" Five response options were offered, ranging from "poor" to "excellent."

The authors' survey asked students to assess their competence on 19 specific ICT tasks. Four response options, ranging from "I don't know how to do this" (scored as 1) to "I can teach others how to do this" (scored as 4) were provided. These measures were used to construct a standardized scale $\operatorname{score}^{4}($ mean $=0$; standard deviation $=1)$, with Cronbach's $\alpha$ of 0.96 .

\section{Attitude towards Computers (Dispositions)}

Only the authors' survey asked about students' dispositions to computers, with six questions:

- I prefer courses where I get to use computers.

- I would avoid a course if I had to use a computer in it.

- I will be able to get a better job if I learn how to use a computer.

- I feel comfortable working with a computer.

- I get annoyed when I use a computer.

- School work is easier with a computer.

These items had a five-point Likert response format ranging from strongly disagree to strongly agree. PCA extracted a single factor; hence our measure of dispositions is the resulting standardized factor score, which has a reliability (Cronbach's $\alpha$ ) of 0.68 .

4. Since the psychometric properties of these items were not known, categorical PCA was used to obtain optimal metric quantifications. The results obtained from a two-dimensional solution indicate that no consecutive responses for any item are tied, so the ordinal criterion for all items is fulfilled. 


\section{HYPOTHESES}

As stated earlier, one objective of our analysis is to assess the extent to which access to, use of, and facility with ICT mirrors the social location of groups within Canadian social structure. Our analytic logic is that if ICT has the potential to mitigate some of the inequities that exist among these groups, then the position of young people on the three components of ICT capital will not precisely mirror their cultural centrality position.

Our working (null) hypothesis in this paper is that access to this capital does mirror the group's position: the closer a group is to the cultural centre, the more effective the members will be in positioning themselves competitively on all three components of ICT resources. That is, they will furnish their homes with more and better ICT technology; they will develop facility in more ICT applications that can be converted to other forms of capital (such as marks and job skills); and they will have a keener understanding of the necessity of ICT skills for their future.

The APS permits us to assess the situation among Canadian youth who claim FNIM ancestry. We expect the following relative positions, from least to most central, to hold:

Inuit $<$ FN on-reserve $<$ FN off-reserve $<$ Métis $<$ FNIM non-identifiers.

In the YITS survey we expect:

FN $<$ African Canadian $<$ Asian $<$ White.

The authors' data contains information on the same groups as YITS, but additionally has information on the Inuit, who are expected to be below FN.

These expectations emerge from the extent of the historically disadvantaged positions of these racial groups, combined with their current levels of integration into the dominant culture. The relative position of Inuit versus on-reserve First Nations derives to some extent from the fact that ICT infrastructure in Nunavut is the least developed, the necessity to compete with Whites is a recent development, and even the notion of status maneuvering seems foreign to the Inuit culture.

\section{Findings}

\section{Socioeconomic and Cultural Profiles}

Before tackling the main issue at hand, it is important to perform additional validating tests about the current location of the population groups in terms of cultural centrality for two reasons. First, while the review of the empirical literature supported the placement of FNIM on the outer 
periphery, visible minorities near the middle, and Whites at the central cultural core, it provided only fragmented information limited to economic outcomes and educational attainment. Second, should we be mistaken in our placement of the various racial identity groups, any subsequent conclusion about the potential of ICT capital to mitigate existing inequities would likewise be in error. Socioeconomic profiles of these groups will also provide a fuller understanding of their material, social, and cultural conditions.

Table 1 provides information from the APS on four aspects of FNIM conditions: economic and education (rows 1-3), retention and importance of aboriginal language (rows 4-6), participation in traditional food

\section{Table 1: Socio-economic Profile of FNIM Peoples}

\begin{tabular}{|c|c|c|c|c|c|}
\hline Percent & Inuit & On-reserve & Off-reserve & Métis & Nonidentifiers \\
\hline $\begin{array}{l}\text { 1. Census family income } \\
\text { (annual \$) }\end{array}$ & 35,779 & 6,851 & 21,129 & 38,188 & 59,514 \\
\hline 2. Unemployment rate & 13.8 & 13.3 & 9.4 & 8.7 & 6.9 \\
\hline $\begin{array}{l}\text { 3. Graduated from high } \\
\text { school* }\end{array}$ & 44 & 45 & 64 & 69 & 82 \\
\hline $\begin{array}{l}\text { 4. Understands or speaks an } \\
\text { Aboriginal language }\end{array}$ & 76 & 79 & 33 & 16 & 3 \\
\hline $\begin{array}{l}\text { 5. First language was Ab- } \\
\text { original and still under- } \\
\text { stands it }\end{array}$ & 68 & 57 & 16 & 5 & 1 \\
\hline $\begin{array}{l}\text { 6. Considers it very import- } \\
\text { ant to keep, learn, or } \\
\text { re-learn their Aboriginal } \\
\text { language }\end{array}$ & 77 & 78 & 41 & 23 & 8 \\
\hline $\begin{array}{l}\text { 7. Hunted in the past } 12 \\
\text { months }\end{array}$ & 51 & 30 & 15 & 16 & 9 \\
\hline $\begin{array}{l}\text { 8. Fished in the past } 12 \\
\text { months }\end{array}$ & 62 & 37 & 34 & 38 & 29 \\
\hline $\begin{array}{l}\text { 9. Gathered wild plants such } \\
\text { as berries and sweet grass } \\
\text { in the past } 12 \text { months }\end{array}$ & 50 & 37 & 28 & 28 & 22 \\
\hline $\begin{array}{l}\text { 10. Trapped in the past } 12 \\
\text { months }\end{array}$ & 10 & 8 & 3 & 2 & 1 \\
\hline \multicolumn{6}{|c|}{ Considers the following to be a problem in their community or neighborhood (\%) } \\
\hline 11. Suicide & 65 & 60 & 37 & 37 & 35 \\
\hline 12 Unemployment & 85 & 93 & 75 & 71 & 64 \\
\hline 13. Family violence & 65 & 78 & 59 & 58 & 55 \\
\hline 14. Sex abuse & 57 & 68 & 48 & 46 & 41 \\
\hline 15. Drug abuse & 77 & 90 & 69 & 69 & 63 \\
\hline 16. Alcohol abuse & 77 & 92 & 75 & 74 & 70 \\
\hline
\end{tabular}

Source: Aboriginal Peoples Survey 2001. All differences between FNIM peoples are statistically significant at the conventional $\mathrm{p} \leq .05$ level.

* Calculated on the basis of those who were not currently attending an educational institution. 
provisioning activities (rows 7-10), and indicators of cultural and community disintegration (rows 11-16).

With respect to family income, we see marked inequalities, ranging from a low family income of under $\$ 7,000$ for First Nations living on reserves, to a high of nearly $\$ 60,000$ among nonidentifiers. For four of the five groups, family income differences mirror cultural centrality as we have constructed it. The Inuit are anomalously located with respect to family income, having an income comparable to that of the Métis, presumably due to the substantially higher cost of living in Canada's northern regions (Kuhn and Sweetman 2002). Both unemployment rates and educational achievement are isomorphic with their postulated position in terms of cultural centrality.

Retention of their own culture through aboriginal language facility powerfully demarcates the different cultural groups, with over three quarters of the Inuit and on-reserve First Nations respondents stating that they understand or speak an aboriginal language, while only 3 percent of respondents who do not claim an aboriginal identity maintain such a skill. On the language issue, we see especially clearly the effect of geography and physical space. On-reserve First Nations peoples are essentially indistinguishable from the Inuit with one exception: considering whether their first language was aboriginal (and they still understand it), we see a greater retention among the Inuit as compared to First Nations peoples living on a reserve (68 percent versus 57 percent, respectively).

Relatively large group differences also characterize the likelihood of engaging in traditional livelihood pursuits such as hunting, fishing, trapping, and gathering wild plants. About half the Inuit report having hunted in the past year, compared to approximately one in ten non-identifiers. With minor exceptions, the likelihood of pursuing any of these traditional activities mirrors our concept of cultural centrality; the closer to the centre, the less likely to engage in traditional livelihood pursuits.

These positive aspects of maintaining cultural diversity through retention of aboriginal languages and engagement in traditional livelihood pursuits is counteracted by patterns in a variety of social problems, such as drug and alcohol abuse, and family and sexual violence. While these measures are not of actual levels of social problems, it is clear that onreserve First Nations peoples live in an atmosphere in which these problems are most widely seen as a concern, followed by the Inuit. For the remaining groups, such an atmosphere decreases with cultural centrality. While one could imagine a world in which those farthest removed from a dominant cultural centre also enjoy the greatest cultural integrity, it seems clear that such a world does not currently characterize Canadian society. 
Considering the profiles as a whole warrants a number of conclusions. The heterogeneity of the conditions of existence between the four groups of FNIM peoples is immense..$^{5}$ In light of this, the typical practice of treating FNIM peoples as one undifferentiated entity is both unwise and unjustified. Further, the differences between on- and off-reserve First Nations peoples are also substantial, usually exceeding those between Inuit and First Nations living on a reserve. This finding corroborates the fundamental necessity of differentiating between the two groups of First Nations peoples, despite their common identity.

All four aspects of FNIM peoples' conditions of existence (labour market, language, livelihood pursuits, and community/cultural problems) are interlocked, and therefore locate the groups in terms of cultural centrality. These four factors contain opposing polarities. Language retention and traditional livelihood pursuits symbolize the positive pole of racial identity attachments, while concern about social problems in the community and dismal labour market outcomes express the negative pole. Breton (1998:69) insightfully noted that FNIM peoples are "pulled in two directions at the same time: towards as much participation as possible in distinct, autonomous communities on the one hand, and towards integration in the larger social structure, on the other." This profile of FNIM peoples' conditions of existence clearly shows the two faces of attachment to racial identities that underlie the approach-avoidance dynamic. What these profiles add to Breton's observation is that the intensity of these incompatible forces is inversely proportional to cultural centrality; in other words, the more peripheral the group, the greater the intensity of both the attracting and repelling forces.

The relative locations of the four groups exhibit a remarkable consistency across all 16 attributes contained in Table 1. With the exception of the income differences between the Inuit and off-reserve First Nations peoples, the reversals are minor. Only with respect to the locations of the Inuit relative to First Nations peoples living on a reserve is the profile indecisive. The latter are consistently most likely to perceive their community to suffer from various social ills, and they have the lowest family income - both factors would theoretically place them as more peripheral than the Inuit. On the other hand, the Inuit are most likely to pursue traditional livelihood pursuits and to maintain a somewhat stronger emphasis on their aboriginal languages - factors that place them in the position of being most distant from the centre. We nevertheless conclude

5. Of course, the heterogeneity of the dominant White group is immense as well. However, given that they are the dominant group, their heterogeneity (in SES, rural-urban location, gender, language) has been well researched and well documented. 
that the Inuit should be considered to be more peripheral than on-reserve First Nations peoples in terms of cultural centrality, based partly on geographic location and partly on the recency, frequency, and density of social interactions with Whites.

Data from the authors' survey and the YITS confirm these patterns for a more focused age group. These data permit comparisons to be made between Inuit, First Nations, African Nova Scotian, Asian, and White students. In these data sets parental education constitutes the primary indicator of parental cultural capital. Table 2 shows that the relative positions of the racial groups partially mirror their assumed cultural centrality, but with some exceptions. In the authors' data the parents of Asian students have higher educational attainments than their White counterparts, while in the YITS they have less education on average than do the parents of African Canadian youth. With respect to their own educational aspirations and expectations however, both data sets lead to the conclusion that Asian youth score even higher than White youth. ${ }^{6}$ The high educational expectations of Asian parents and the high academic

Table 2: Profile of Educational Factors, by Population Group Membership

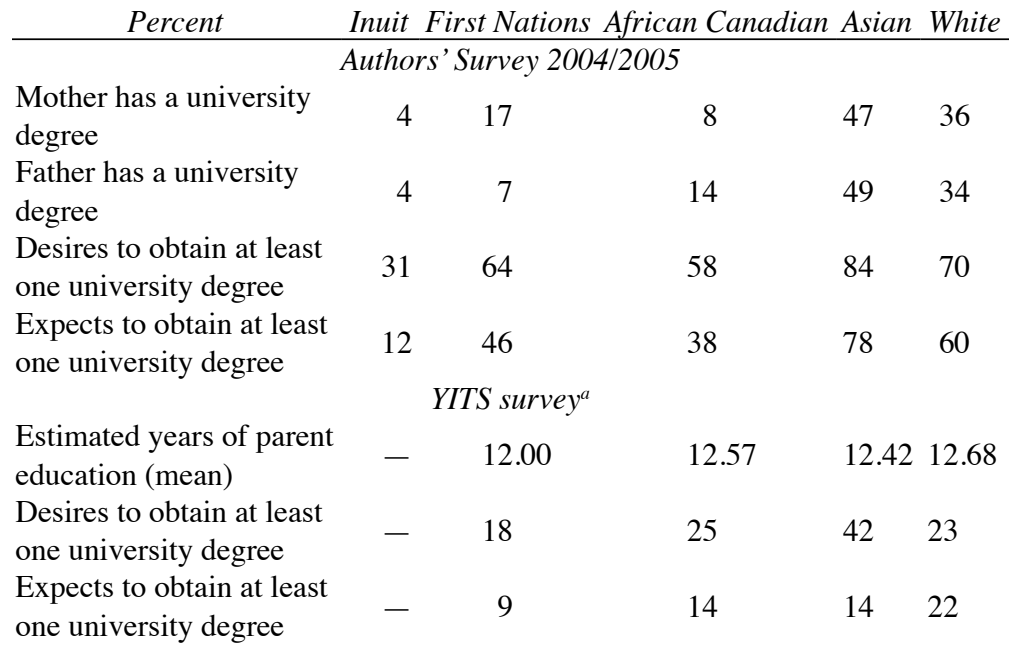

All differences between racial groups are statistically significant at the conventional $(\mathrm{p}<$ .05) level.

a. The YITS survey does not include the Inuit; all First Nations respondents in YITS are off-reserve.

6. A number of alternative measures of parental education, such as estimated years of education of mother and father, and mean parental education were calculated. Additionally, both educational aspirations and expectations were converted into the estimated number of years. The relative positions of the cultural groups are robust with respect to these alternative measures. 
performance of their children is noted in both Canadian and American studies (Chow 2000; Pong 1997; Sun and Li 2001). Almost 10 percent more First Nations than African descent mothers have attained a university degree, although the expected order between these two groups is maintained when looking at father's education and the YITS data.

In all groups, young people are substantially more likely to both aspire to and expect to obtain more education than their parents. At the same time, the rank order of aspirations and expectations of the population groups largely mirrors parental educational accomplishments. In other words, the aspired and/or expected educational attainment of the youth tend to reproduce (albeit at a higher level) their parents' current educational attainment.

Taken together, these findings suggest that on the educational front, the next generation of adults will, with the exception of Asians, essentially reproduce the social status hierarchy of the current generation. The question in this paper, however, is whether ICT has the potential to modify this hierarchy by helping disadvantaged groups reduce or overcome some traditional inequalities that inhibit their educational attainment and occupational outcomes. We turn now to this question.

\section{Technological Capital}

Figures 1 and 2 (based on the APS) show that both using a computer or the Internet in the past year, and whether one did that at home, form the following inequalities:

\section{Inuit $\approx$ On-reserve $\mathrm{FN}<$ Off-reserve FN $<$ Métis $<$ No FNIM identity.}

These inequalities mirror integration into the White culture, with the Inuit being least integrated and those claiming no FNIM identity most integrated. Computer use and home access follow the pattern reported above, even when rural-urban location is controlled, suggesting that use patterns reflect more than geographic barriers to Internet access.

The authors' data permit us to assess in greater detail the configuration of ICT in the home. About 40 percent of White homes have two or more home computers as well as a high-speed Internet connection, as do over half of Asian homes, but only 4 percent of Inuit homes (see Figure 3 ). On the other hand, one in three Inuit but one in a hundred White students live in a household that is without a computer (not shown). These results suggest that ICT is likely to entrench current inequalities.

Of course, the mere availability of home ICT does not necessarily mean that young people will avail themselves of such facility, although previous research demonstrates that they do. 
Figure 1: FNIM and Computer Use in the Past Year

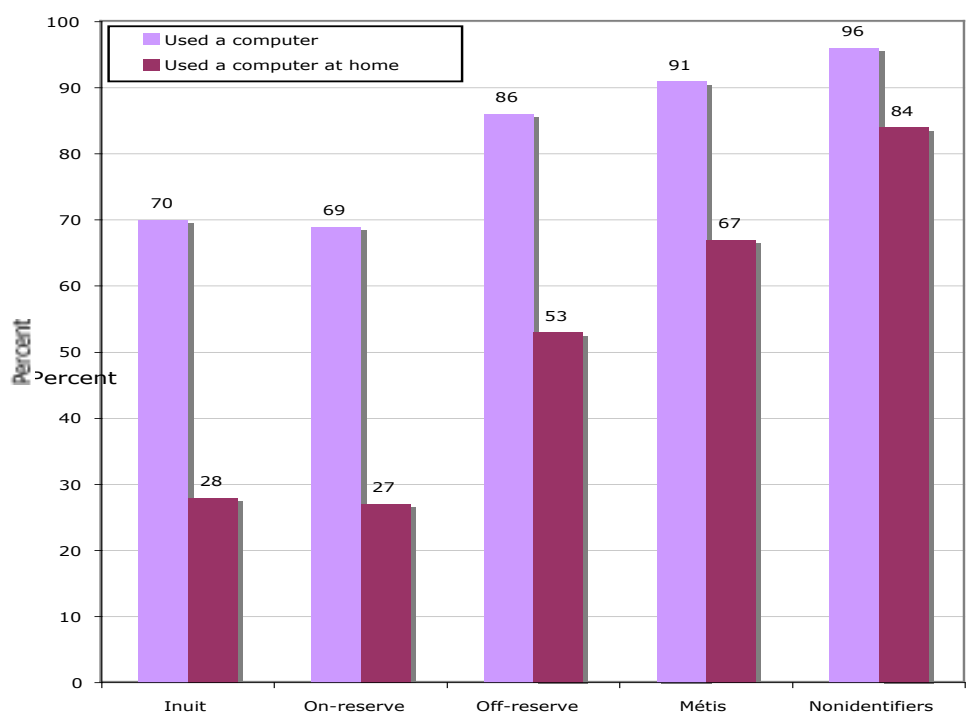

Source: Aboriginal Peoples Survey 2001

\section{Figure 2: FNIM and Internet use in the Past Year.}

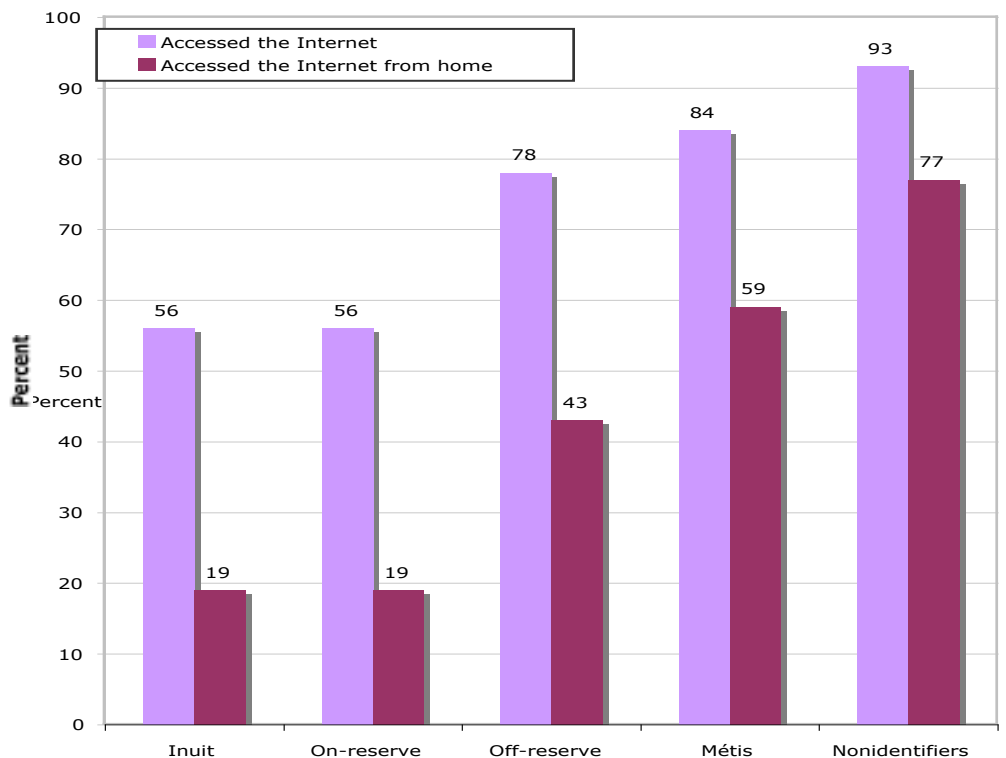

Source: Aboriginal Peoples Survey 2001 
Figure 3. Population Group Membership and Access to Home Internet with at least Two Computers

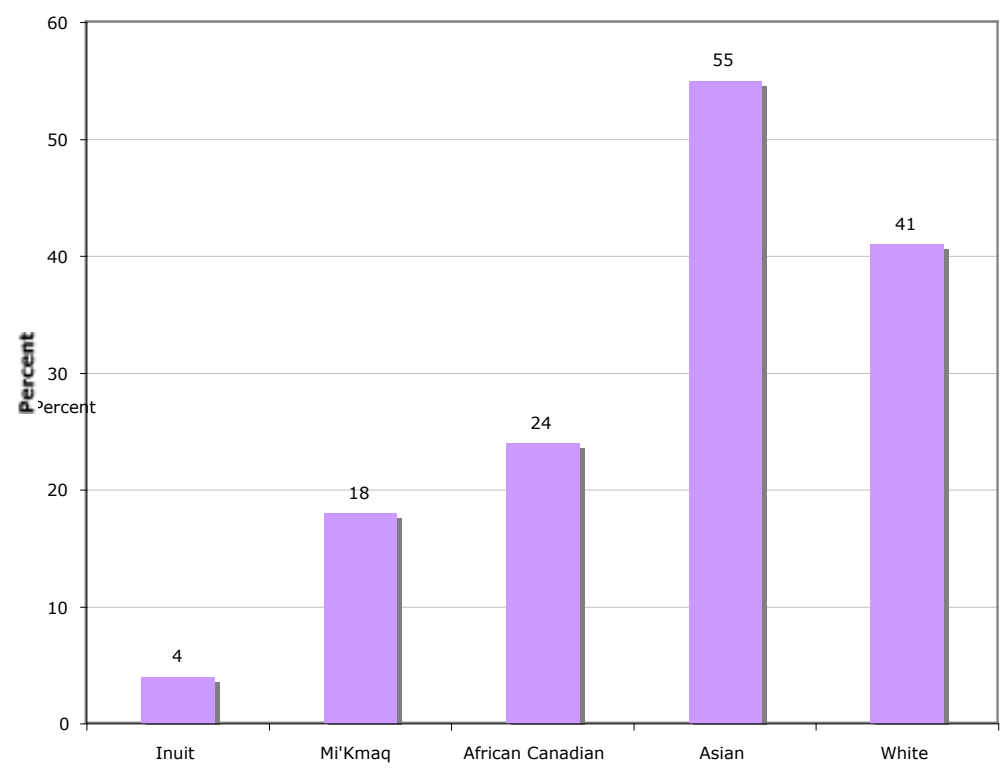

Source: Authors' Survey 2004/2005

\section{Human Capital ICT Skill}

While direct assessment on actual ICT skills is not available, we do have self-reported levels of ability to perform a large variety of distinct tasks with ICT. The first row of Table 3 shows that, with the exception of a reversal between Asians and Whites, the mean self-reported ICT skill acquisition mirrors cultural centrality. Since skill scores were standardized, the results indicate that the self-reported ICT skills of Inuit students are a full standard deviation below the mean, while those of Asian and White youth are approximately two-fifths of a standard deviation above the mean. At a bivariate level, using ANOVA, cultural centrality accounts for 35 percent of the variance in ability to perform a variety of tasks on the computer. The same rank order is found in the YITS data (rows 4 and 5), with First Nations at the bottom and Asian youth at the top.

\section{Dispositions}

The third row of Table 3 also shows that student dispositions towards ICT reflect, in perfect rank-order, the distance from the cultural centre. Despite this, it is perhaps best to conclude that cultural centrality has at 
Table 3: Population Group Membership and ICT Use, Skills and Attitudes (Means)

\begin{tabular}{|c|c|c|c|c|c|}
\hline Authors' Survey 2004/2005 & Inuit & $\begin{array}{l}\text { First } \\
\text { Nations }\end{array}$ & $\begin{array}{l}\text { African } \\
\text { Canadian }\end{array}$ & Asian & White \\
\hline $\begin{array}{l}\text { 1. Mean ability to perform a variety of } \\
\text { tasks on the computer }\end{array}$ & -1.04 & -.24 & .07 & .42 & 39 \\
\hline $\begin{array}{l}\text { 2. Self-rated computer ability on a scale } \\
\text { of } 1 \text { (no ability) to } 7 \text { (expert ability) }\end{array}$ & 4.08 & 4.97 & 5.07 & 5.23 & 5.27 \\
\hline 3. Attitude towards computers & -0.26 & -0.24 & -0.06 & 0.04 & 0.12 \\
\hline \multicolumn{6}{|c|}{ YITS survey ${ }^{a}$} \\
\hline $\begin{array}{l}\text { 4. Self-rated computer ability in } 2000 \text { on } \\
\text { a } 1 \text { (poor) to } 4 \text { (excellent) scale }\end{array}$ & - & 2.88 & 2.86 & 3.21 & 3.06 \\
\hline $\begin{array}{l}\text { 5. Self-rated computer ability in } 2002 \text { on } \\
\text { a } 1 \text { (poor) to } 4 \text { (excellent) scale }\end{array}$ & - & 3.86 & 3.90 & 4.36 & 4.19 \\
\hline
\end{tabular}

All differences between racial groups are statistically significant at the conventional $(\mathrm{p}<.05)$ level. a. The YITS survey does not include the Inuit; all First Nations respondents in YITS are off-reserve.

most a minor bearing on attitudes towards computers and their role in young people's future, since it accounts for only 3 percent of the variance.

\section{Multivariate Analysis}

The next step is to examine the nature and extent of racial gaps in ICT home access and skill acquisition after controlling for a variety of background factors. We present two sets of regression equations. The first set (using the APS) addresses home access to ICT, while the second set (using the authors' survey) does so for ICT skill acquisition. Table 4 provides three models for home ICT access. The dependent variable is a 3-point variable where 0 indicates having no computer in the home, 1 indicates having a home computer but no Internet, while a 2 indicates also having an Internet connection in the home. ${ }^{\text {? }}$

Model 1 provides the baseline unadjusted gaps in home ICT among FNIM youth. The relative positions of the FNIM groups are the same as in the bar charts. Approximately 11 percent of the variance in home access to ICT is associated with membership in FNIM groups.

Model 2 adds measures relating to maintaining facility in an aboriginal language and stressing the importance of maintaining such facility.

7. We ran parallel multivariate logistic regressions with two (dichotomous) dependent variables (whether the home is equipped with a computer and whether the home is connected to the Internet). The findings presented in Table 4 are robust with respect to the pattern of effects of all the independent variables. 
Table 4: OLS Models of Home ICT Resources

\begin{tabular}{|c|c|c|c|c|c|c|c|c|c|}
\hline \multirow{2}{*}{ Nonidentifiers } & \multicolumn{3}{|c|}{ Model 1} & \multicolumn{3}{|c|}{ Model 2} & \multicolumn{3}{|c|}{ Model 3} \\
\hline & $b$ & s.e & $\beta$ & $b$ & s.e & $\beta$ & $b$ & s.e & $\beta$ \\
\hline $\begin{array}{l}\text { Nonidentifiers } \\
\text { (omitted reference } \\
\text { group) }\end{array}$ & 1.40 & 0.027 & & 1.32 & 0.027 & & 1.18 & 0.029 & \\
\hline Inuit & -1.07 & 0.034 & -0.36 & -0.71 & 0.037 & -0.24 & -0.37 & 0.061 & -0.12 \\
\hline On-reserve & -0.92 & 0.030 & -0.45 & -0.64 & 0.031 & -0.32 & -0.40 & 0.035 & -0.20 \\
\hline Off-reserve & -0.68 & 0.030 & -0.34 & -0.50 & 0.030 & -0.25 & -0.34 & 0.029 & -0.17 \\
\hline Métis & -0.37 & 0.030 & -0.18 & -0.30 & 0.029 & -0.15 & -0.21 & 0.028 & -0.10 \\
\hline \multicolumn{3}{|c|}{$\begin{array}{l}\text { Facility with and importance of } \\
\text { aboriginal language }\end{array}$} & & -0.177 & 0.007 & -0.22 & -0.11 & 0.007 & -0.14 \\
\hline \multicolumn{4}{|c|}{ Arctic } & & & & -0.38 & 0.058 & -0.13 \\
\hline \multicolumn{4}{|c|}{ Rural } & & & & -0.24 & 0.016 & -0.13 \\
\hline \multicolumn{6}{|c|}{ Graduated from high school or currently attending school } & & 0.41 & 0.014 & 0.21 \\
\hline \multicolumn{6}{|c|}{ Low income household } & & -0.45 & 0.019 & -0.19 \\
\hline \multicolumn{6}{|c|}{ Missing value on low income* } & & -0.20 & 0.023 & -0.11 \\
\hline Adjusted $\mathrm{R}^{2}$ & & 0.105 & & & 0.138 & & & 0.225 & \\
\hline
\end{tabular}

Source: APS (youth ages 15-24). All parameter estimates are statistically significant $(\mathrm{p}<.05)$.

* To maintain the maximum number of cases, the mean of the independent variables was substituted for respondents with missing values and a dichotomous variable constructed to indicate the missing value status. Statistics Canada does not apply the low income definition to on-reserve First Nations peoples. Hence the negative parameter estimate of the missing value indicator represents the fact that these households are less likely to be equipped with ICT.

A negative association $(\beta=-.22)$ is found with respect to home access to ICT (increasing the explained variance from 10.5 percent to 13.8 percent), indicating that youth who maintain facility in an aboriginal language and believe in its importance live in homes that are less likely to be equipped with ICT. In other words, language may be a salient mechanism underlying the racial inequalities in access to ICT. This result may be unsurprising given the English dominance of the Internet. ${ }^{8}$ Model 3 adds the significant control variables, such as geographic location, youth's educational attainment, and living in a low-income household. With these factors included other variables, including gender, had only trivial effects and therefore were excluded from the model. As expected, these factors show substantial relationships with home access to ICT. Further, individually and collectively they reduce the racial inequalities in such access. What is more important to our argument is that a) the gaps are not eliminated, and b) the language effect, although diminished, remains appreciable $(\beta=-.14)$. Using the authors' survey, three regression models

8. It is not simply a matter of lack of familiarity with the English language. In the authors' study, for example, all respondents spoke English and opted to complete the survey in English, even though the choice of doing so in their native tongue was made available. 
of ICT skill acquisition were assessed. Since we have already presented the unadjusted skill inequalities between the different racial groups (see Table 3, row 1) the first model directly assesses the language factor. The distribution of the sample by grade differed by school, and since grade in school is related to ICT skill acquisition, grade level is also added to this model to correct for this sampling difference.

The second model introduces three family factors: mother's education, number of computers in the home, and whether there is access to the Internet at home. The third model incorporates individual student attributes relevant to ICT skill acquisition. These include their disposition toward computers and the amount of time they devote to ICT activities. In Models 2 and 3, the independent variables have been centered to the overall sample means. This permits us to estimate what the differences between the racial groups in ICT skill acquisition would be if they were identical on these variables. Table 5 presents the results.

As in the APS, facility in and importance of a language other than French or English has a negative effect (Model 1), suggesting that this

Table 5: OLS Models of ICT Skill Acquisition

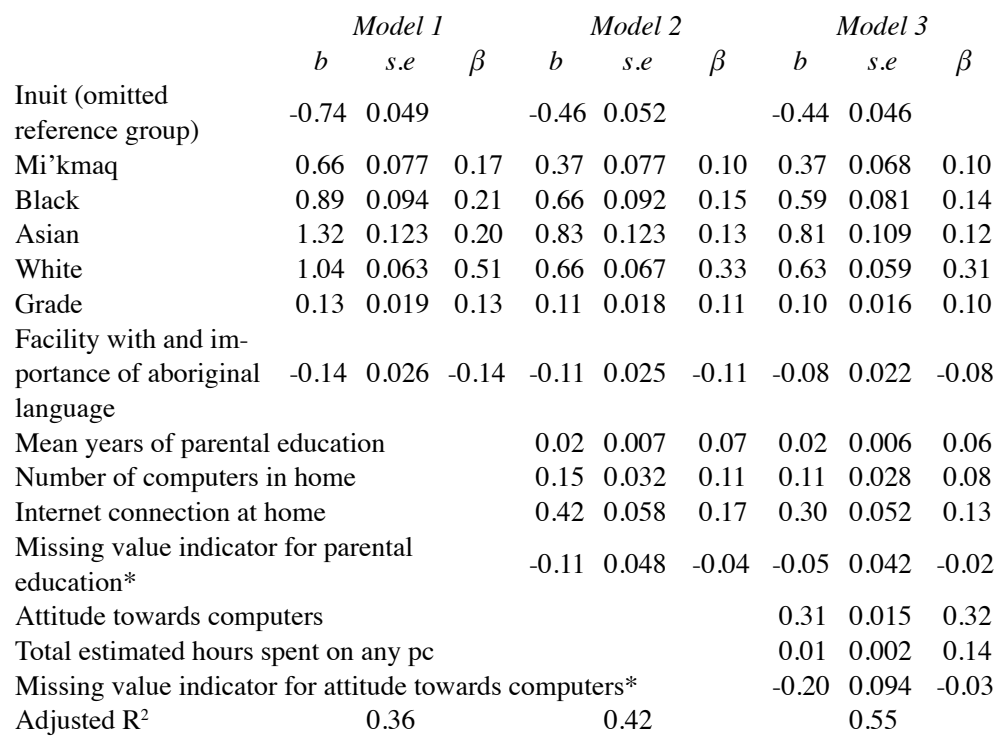

Source Authors' Survey 2004/2005. All parameter estimates are statistically significant ( $<$.05) except for the missing value indicator for parental education in the third model.

* To maintain the maximum number of cases, the mean of the independent variables was substituted for respondents with missing values and a dichotomous variable constructed to indicate the missing value status. The negative parameter estimates reveal that respondents with missing values on these variables had lower ICT skills. 
form of identification with one's culture may impede acquisition of ICT skills. The question that Model 2 helps answer is the extent to which these large population group differences in ICT skill acquisition are attributable to differences in familial resources. Comparing the population group slopes shows that all of them are smaller in Model 2, indicating that such resources account for some of the population group differences in ICT skill acquisition. This is hardly surprising, since we documented earlier that population groups differed systematically in the prevalence of parental cultural and ICT capital. Our regression results permit us to estimate the proportion of subsequent differences in students' ICT skills can reasonably be attributed to differences in parental resources.

The third model supports two additional conclusions. First, individual disposition and time spent on ICT activities are important factors among all groups in determining their ICT skill acquisition. These factors increase the explained variance from 42 percent to 55 percent. Second, and more importantly, these attributes have but a modest impact on reducing the intergroup differences in ICT skill acquisition, given that the population group differences are not much further reduced from what was found in Model 2. That is, dispositions and time spent on ICT activities account for substantial variation in ICT skill acquisition within racial groups, but not between them. In the final model, we still see the following rank-order of inequality in ICT skill acquisition:

Inuit $<$ FN $<$ Black $<$ White $<$ Asian.

\section{Conclusion}

In this paper we introduced the concept of cultural centrality as a way of examining the current racialized structure of Canadian society. Our analysis revealed large inequalities of condition among these groups. Not only are these inequalities immense, they cluster to reinforce a structure of inequality that permits us to conceptualize population groups as located at different positions along a cultural centrality continuum. Of special note is that differences among FNIM peoples appear to be even larger than the differences between them collectively and other visible minorities. Further, the differences between FNIM peoples of distinct cultural identity reflect consistent patterns of inequality of conditions between them.

To assess the patterns of ICT capital acquisition we examined the extent of acquisition of various forms of such capital among the youth of the racial groups, showing that in all its forms (technological, human skills, and dispositions) ICT capital was strongly and consistently related 
to racial identities, and isomorphic with a group's hypothesized location on the cultural centrality continuum. Only among Asian students is there a sign that ICT capital accumulation might represent a pathway to improve their collective position in the next generation. This is not the case for FNIM or African Canadian youth.

We base these conclusions on the fact that a) the between groups differences in ICT skill acquisition was only partially explained by differences in family resources, such as parental education and home access to computers and the Internet; b) maintaining one's own language and a group's distance from the cultural centre were both related to the acquisition of ICT skills and resources; and c) inequalities in ICT skill acquisition could not be explained by differences in dispositions towards ICT, nor by time spent on ICT activities (nor rural-urban differences).

The Canadian, provincial, and territorial governments, in cooperation with schools and school boards, have made a laudable and impressive commitment to provide an ICT infrastructure to all schools across Canada. This was done in part to ensure Canada's future economic competitiveness and in part to minimize future inequalities. Our analysis demonstrates that, if anything, ICT has entrenched rather than reduced racial inequalities. It is perhaps appropriate to ponder at this point why ICT capital remains so unequally distributed by cultural identities, especially since public investment in ICT seems to have countered many of the disadvantages in access experienced by rural youth (Looker and Thiessen 2002).

It must be remembered that equality of access to ICT and other resources, even if it were to exist, would represent only a necessary but not a sufficient condition for equalizing outcomes. In other words, we are not suggesting that simply providing access to ICT and related skills will erase long-standing social and economic disadvantage. Rather, we are documenting the pervasive nature of these inequities along cultural and racial lines. That is, access to ICT as the "new literacy," which is being touted as critical to youth success in the information society, reflects these cultural and racial differences. What is more, we highlighted the importance of recognizing key differences among the "minority" groups in Canada - differences between the Inuit and other First Nations groups, differences between on-reserve and off-reserve First Nations youth, and differences between these groups and other "visible minorities." Of course there are also important differences between the various First Nations groups based on the culture and history of each group. However, it is beyond the scope of this analysis to be able to explore these differences. One counter to this relatively negative set of findings is research that shows that the Inuit spend more per capita on 
home entertainment technology than other Canadians (Thomas 2005). Thomas's suggestion is that with broadband, introduced into Nunavut in 2004-2005, computers could become the new "home entertainment" unit, embraced by the Inuit. However, our data show little indication of the Inuit using ICT more than others; rather, as the group furthest from the cultural centre they seem to use it the least.

There is also the thorny issue of the push-pull of conformity to the cultural centre. It is fairly clear that the distance African Canadian youth are from the centre, or their "separateness," provides them with few if any advantages. First Nations peoples and the Inuit have the complex task, on the one hand, of trying to maintain and strengthen their traditional cultures and ways of life while also, on the other hand, trying to improve their social and economic positions. The critical question then becomes why closeness to the cultural centre seems to be a prerequisite for economic and social advantage. Clearly there is a need for both more research and for a clearer understanding of the barriers that face cultural and racial minorities before we conclude that they are doomed to cultural marginality, that cultural distance from the centre must inevitably mean economic and social disadvantage, or that ICTs have little potential to change this state of affairs.

Based on our analysis of cultural centrality and ICT access and use among Canadian youth, the racial/cultural groups we examined can be arranged on a continuum of distance from the cultural centre, in terms of a range of social, economic, and cultural indicators. We also found, with few exceptions, that access, use, and development of competency with ICT mirrors this continuum. Why is this important?

These results are particularly important at this stage of Canada's development given the growing importance of aboriginal issues in Canada. On the one hand, there is the well documented fact that the aboriginal population, particularly the Inuit population in the northern territories, is the fastest growing portion of the Canadian population (Statistics Canada 2005). The main contributing factor to this growth is high levels of fertility - so the growth is in youth - the age group most affected by access to ICT for their futures. The Arctic has also increased in strategic importance in recent years (Canadian Department of Foreign Affairs and International Trade 2000), as waterways in the North become more accessible and as geological exploration reveals more and more resources that could be developed. Added to these strategic issues is the ongoing commitment in Canada to equity and a concern that all young people be prepared for full participation in a "knowledge-based society." To the extent that digital divides of access and key competencies persist on the 
basis of one's social, cultural, and racial background, this is grounds for concern.

Our results are also, of course, relevant to those doing research relating to ICT, whether they design and fund large-scale surveys or analyze the data. We have found not only large and persistent differences between the dominant group of Whites with European background and all others, we have also found important differences between the different groups. In other words, if we are to understand the ongoing ways certain groups are marginalized in our society, we need to (a) gather and (b) analyze detailed information on group identification, differentiating between onand off-reserve First Nations groups, including the Inuit in more surveys, and identifying the ways that visible minority groups differ in terms of their history and their social location within Canada.

Clearly we are a long way from digital equity in Canada. We are perhaps even further away from harnessing any form of ICT capital to reduce current population group inequalities. Although ICT has the technological capability to be instrumental in this respect, careful consideration is now required of the barriers to effective capitalization of its potential.

\section{REFERENCES}

Alkalimat, Abdul and Kate Williams. 2001. Social capital and cyberpower in the African American community. In L. Keeble and B. Loader, eds., Community Informatics: Community Development Through the Use of Information and Communications Technologies. London: Routledge. Accessed January 29, 2006: http://www.communitytechnology.org/cyberpower/.

Bourdieu, Pierre and Luc Boltanski. 1978. Changes in social structure and changes in the demand for education. Pp. 197-227 in S. Giner and M. S. Archer, eds., Contemporary Europe: Social Structure and Cultural Patterns. London: Routledge \& Kegan Paul.

Breton, Raymond. 1998. Ethnicity and race in social organization: Recent developments in Canadian society. pp. $60-115$ in R. Helmes-Hayes and J. Curtis, eds., The Vertical Mosaic Revisited. Toronto: University of Toronto Press.

Canadian Department of Foreign Affairs and International Trade. 2000. The Northern Dimension of Canada's Foreign Policy. Ottawa. Accessed November 1, 2007. http://www.maeci-dfait.gc.ca/circumpolar/publicationsen.asp

Chakraborty, Jayajit and M. Martin Bosman. 2005. Measuring the digital divide in the United States: Race, income and personal computer ownership. Professional Geographer 57:395-410. 
Chow, Henry P. 2000. The determinants of academic performance: Hong Kong immigrant students in Canadian schools. Canadian Ethnic Studies 32:105-110.

Geschwender, James A. and Neil Guppy. 1995. Ethnicity, educational attainment, and earned income among Canadian-born men and women. Canadian Ethnic Studies 27:67-84.

Gosine, Kevin. 2000. Revisiting the notion of a 'recast' vertical mosaic in Canada: Does a post secondary education make a difference? Canadian Ethnic Studies 32:89-110.

Graham, Stephen. 2002. Bridging urban digital divides: Urban polarisation and information and communications technologies (ICTs). Urban Studies 39:33-56.

Hoffman, Donna L., Thomas P. Novak, and Ann E. Schlosser. 2001. The evolution of the digital divide: Examining the relationship of race to Internet access and usage over time. Pp. 47-97 in B.M. Compaine, ed., The Digital Divide: Facing a Crisis or Creating a Myth? Cambridge, Mass.: MIT Press.

Hou, Feng and T.R. Balakrishnan. 1996. The integration of visible minorities in contemporary Canadian society. Canadian Journal of Sociology 23:307326.

Ipsos-Reid. 2005. Parents connect Internet at home with their child's potential success at school. September 23, Canadian Ipsos-Reid Express. Accessed March 14, 2006: http://www.ipsos-na.com/news/pressrelease. cfm?id=2794.

Kuhn, Peter and Arthur Sweetman. 2002. Aboriginals as unwilling immigrants: Contact, assimilation and labour market outcomes. Journal of Population Economics 15:331-355.

Lenhart, Amanda. 2003. The Ever-Shifting Internet Population: A New Look at Internet Access and the Digital Divide. Washington, D.C.: The Pew Internet and American Life Project. Accessed July 16, 2005. http://www. pewinternet.org/pdfs/PIP Shifting Net Pop Report.pdf

Looker, E. Dianne and Victor Thiessen. 2002. The Digital Divide in Canadian Schools: Factors Affecting Student Access to and use of Information Technology. Council of Ministers of Education, Canada. Accessed November 2, 2007. http://www.cmec.ca/stats/pcera/RSEvents02/main en.htm.

Pendakur, Krishna and Ravi Pendakur. 2002. Colour my world: Have earnings gaps for Canadian-born ethnic minorities changed over time? Canadian Public Policy 28:489-512.

Pong, Suet-Ling. 1997. Family structure, school context, and eighth-grade math and reading achievement. Journal of Marriage and the Family 59:734746.

Porter, John. 1965. The Vertical Mosaic: An Analysis of Social Class and Power in Canada. Toronto: University of Toronto Press. 
1968. The economic elite and the social structure in Canada.Pp. 754-769

in B.R. Blishen, F.E. Jones, K.D. Naegele, and J. Porter, eds., Canadian Society: Sociological Perspectives. Toronto: MacMillan.

Siggner, Andrew J. and Rosalinda Costa. 2005. Aboriginal Conditions in Census Metropolitan Areas, 1981-2001. Trends and Conditions in Census Metropolitan Areas (Catalogue No. 89-613-MIE, No. 008). Ottawa: Statistics Canada.

Statistics Canada. 2003a. Aboriginal Peoples Survey 2001: Concepts and Methods Guide. Ottawa: Minister of Industry. 2003b. Youth in Transition Survey (YITS) 18-20 Year Old Cohort: Cycle 1 User Guide. Ottawa: Statistics Canada. 2005. Canada's Aboriginal Population in 2017: The Daily, June 28, 2005. Ottawa: Statistics Canada.

Sun, Yongmin and Yuangzhang Li. 2001. Marital disruption, parental investment, and children's academic achievement: A prospective analysis. Journal of Family Issues 22:27-62.

Thomas, Lorraine. 2005 Director, Nunavut Broadband. Personal communication.

Turow, Joseph and Lilach Nir. 2000. The Internet and the family 2000: The view from parents; the view from kids. Pp. 1-35 in A Report from The Annenberg Public Policy Center, University of Pennsylvania. Accessed September 3, 2002. http://www.eric.ed.gov/ERICDocs/data/ericdocs2sql/ content storage 01/0000019b/80/16/c5/d3.pdf.

Victor Thiessen is a Professor Emeritus and Academic Director of the Atlantic Research Data Centre at Dalhousie University and adjunct Professor at the University of Stellenbosch. His current investigations focus on the various pathways along which young people navigate their way between schooling and employment. He has considerable experience analyzing large scale data sets and in both the design and analysis of survey research.

Victor.Thiessen@Dal.Ca

E. Dianne Looker is a Tier 1 Canada Research Chair in Equity and Technology at Mount Saint Vincent University where she is Professor of Sociology, and adjunct Professor at Dalhousie University. She has for decades researched equity issues as they relate to youth, focusing particularly on gender and rural-urban differences. She has numerous publications (many with Thiessen) in the academic and policy literature.

Dianne.Looker@msvu.ca 